\title{
Surgical decompression of arachnoid cysts: a study on 44 pediatric patients
}

\author{
A. Tascu', Simona Mihaela Florea ${ }^{2}$ \\ ${ }^{1}$ Assist. Prof. at the Universtity of Medicine and Pharmacy "Carol Davila", Head of \\ the $1^{\text {st }}$ Neurosurgical Departmpent at the Clinical Emergency Hospital "Bagdasar- \\ Arseni", Bucharest, Romania \\ ${ }^{2}$ Student, Universtity of Medicine and Pharmacy "Carol Davila", Bucharest, \\ Romania
}

\begin{abstract}
Background: There are yet to clarify some aspects regarding the surgical indications and surgical methods that are at choice for treating ACs. The purpose of the study is to contribute to the ongoing debate on the most appropriate treatment.

Materials and methods: We included in the study 44 pediatric patients (aged $<18$ years), operated for ACs in the Neurosurgery I Department, of the Emergency Clinical Hospital "BagdasarArseni" in Bucharest, during the period January 2003 to December 2012. The surgical methods were either a craniotomy or cyst shunting. The information regarding these patients was retrospectively assessed based on their clinical and imaging records, and cross checked with the OR protocols. Treatment efficiency was evaluated considering postoperative clinical status, imaging appearance and postoperative complications.
\end{abstract}

Results: $84.1 \%$ of the patients reported postoperative disappearance or reduction of symptoms, while 13.6 had the same complaints as prior surgery. Only one patient experienced worsening of symptoms. Follow-up imaging showed cyst disappearance in $29.5 \%$ patients and cyst reduction in $61.4 \%$ patients. $9.1 \%$ had no change in cyst volume. Craniotomy correlated with a better imaging appearance $(p=0.02)$. There was no correlation between improved clinical status and cyst fluid reduction $(p=0.6) .9$ patients $(20.4 \%)$, all with temporal cysts, experienced postoperative complications, and 7 of them $(15,9 \%)$ needed surgery. There was no severe or permanent dysfunction in any of the patients. $42.8 \%$ of the cyst shunting patients suffered postoperative complications, whereas only $10 \%$ of the craniotomy patients did.

Conclusion: Cyst decompression results in significant clinical improvement and it can be performed with little risk for severe complications. Craniotomy seems to be a better surgical treatment option than cystoperitoneal shunt, with a better neuroimaging appearance and a lower complications rate.

Key words: Arachnoid cyst, pediatric, shunting, craniotomy

\section{Introduction}

Arachnoid cysts (ACs) are benign congenital malformations, formed by the splitting or duplication of the arachnoid membrane, allowing a clear fluid 
resembling normal cerebrospinal fluid to fill in the space crated $(1,2,3)$. They are due to an increased pulsation of the cerebrospinal fluid (CSF) (4, 5). They count for approximately $1 \%$ of the intracranial pathology, being most frequently located in the middle cranial fossa (about half of the ACs) and the cerebellopontine angle (CPA) $(2,3,4,6)$, and they appear to affect more males than females $(7,8)$. The clinical presentation of ACs is variable, depending on the cyst location and the importance of the mass effect exerted on the surrounding nervous structures $(1,2,6,9-11)$. Most of the patients present with nonspecific symptoms such as headache, dizziness or balance impairment, or symptoms of increased intracranial pressure $(3,6)$. The positive diagnosis is set through cerebral imaging (CT scan or MRI), and it reveals a sharply demarcated, non-enhancing, extra-axial cyst, with density/signal similar to the CSF $(12,13)$. The main procedures to treat arachnoid cysts are stereotactic punction, cystoperitoneal shunting, craniotomy followed by radical resection and marsupialisation of the cyst in the subarachnoid space and neuroendoscopic fenerstration of the cyst. The surgical indications for ACs, as well as the surgical procedures elected remain a controversial subject $(1,2,8,15,14-22)$. Arachnoid cysts can complicate with rupture/hemorrhage, especially encountered in large cysts and mostly associated with minor head trauma in the last month $(1,2,20,23,24)$.

\section{Material and methods}

Patients characteristics: the study includes 44 patients, 30 boys (68\%) and 14 girls $(32 \%)$ - sex ratio $\mathrm{B}: \mathrm{G} \approx 2,14: 1$ - that had been operated in our department either by craniotomy or cystoperitoneal shunting. Mean age at admission was 9.36 years (median=9.5, range 1-17). Mean follow-up period was 17.3 months (range 3-62).

Study type and database: the present study is a retrospective, observational, analytic study that includes all pediatric patients (age $<18$ years) operated for an arachnoid cyst during the period January 2003 to December 2012, in the 1st Neurosurgery Department of the Clinical Emergency Hospital "Bagdasar-Arseni" in Bucharest. The patient information was extracted from the clinical and imaging records in the department's database, and cross checked with the OR protocols. The patients complete medical records offered information on: demographic data, subjective complaints, clinical finding at admission and during the in hospital period, imaging aspect, dimensions and location of the ACs, Galassi type for sylvian fissure cysts, complications present at admission, type of surgical procedure, postoperative neuroimaging either following the first 72 hours after surgery or at follow-up, 3 months from surgery.

Criteria for surgical treatment: symptoms related to the cysts were found in 41 patients $(93 \%)$, while 2 other patients were asymptomatic, but with Galassi type III ACs, exerting a significant mass effect on the adjacent brain structures. One patient had a large chronic subdural hematoma, asymptomatic, that was diagnosed during a check-up, after a history of repeated head trauma in the past month.

Decompression method: most of the patients $(68 \%)$ were performed a craniotomy under general anesthesia, cyst membrane excision in the parts where it wasn't adherent to the brain matter. The large bridging veins that presented the risk 
of rupture and hemorrhagic complications postoperatively were coagulated. The normal CSF flow was reestablished by fenestrations that create communications with the posterior cranial fossa and the basal cisterns. The rest of the patients included in the study (32\%) had a cystoperitoneal shunt, that drained the fluid in the cyst into the peritoneal cavity, thus relieving the pressure inside the cyst. This procedure was also performed under general anesthesia.

Treatment evaluation: the efficiency of the surgical treatment performed on each patient was evaluated considering 3 parameters - the clinical presentation postoperative (cuantified by the clinical outcome status $=$ COS scale), the neuroimaging aspect at the 3 months postoperative examination (evaluated by the imaging outcome aspect $=$ IOA scale), and the presence of postoperative complications or reoperation due to complications or failure of the primary intervention. The COS and IOA categories are detailed in Table 1.

Statistical analysis: the statistical data was analyzed with Office 2007 Excel and CDCs Epi Info 7 for Windows. The contingency tables statistical significance was analyzed with Persons chi square test and Fisher exact ( $\mathrm{p}$ level was 0.05 , confidence interval $-\mathrm{CI}=95 \%)$.

\section{Results}

Cyst location: inside the patients group included in our study, most of the patients $(82 \%)$ had a sylvian fissure cyst, followed by frontal arachnoid cysts (14\%) and PCA arachnoid cysts (4\%). Details on cyst locations are presented in Table 2. No other cyst locations presented criteria for surgery.

Main clinical symptoms: with the exception of 3 patients, all patients presented with symptoms related to the cyst. The most frequently encountered symptoms were headache (90.9\%), epilepsy (29.55\%) and dizziness/balance impairment (29.3\%). One patient presented a with motor deficiency in the right side of the body, and two patients complained of personality changes. Table 3 summarizes the frequency of symptoms categorized by cyst location.

TABLE 1

COS and IOA

\begin{tabular}{|l|l|}
\hline COS & $\begin{array}{l}\text { COS1: no or minor postoperative } \\
\text { symptoms }\end{array}$ \\
\cline { 2 - 2 } & $\begin{array}{l}\text { COS2: relief of the symptoms presented } \\
\text { preoperatively }\end{array}$ \\
\cline { 2 - 2 } & $\begin{array}{l}\text { COS3: no change in the clinical } \\
\text { presentation postoperatively }\end{array}$ \\
\cline { 2 - 2 } & COS4: more complaints postoperatively \\
\hline IOA & IOA1: cyst no longer visible \\
\cline { 2 - 2 } & IOA2: decreased cyst volume \\
\cline { 2 - 2 } & IOA3: no change in cyst volume \\
\hline
\end{tabular}

TABLE 2

Cyst location

\begin{tabular}{|l|c|c|c|}
\hline Location & Side & $\begin{array}{c}\text { Number of } \\
\text { patients }\end{array}$ & $\begin{array}{c}\text { Percentage } \\
\text { of patients }\end{array}$ \\
\hline Temporal & Left & 14 & $31.82 \%$ \\
& Right & 12 & $27.28 \%$ \\
\hline Frontal & Left & 3 & $6.82 \%$ \\
& Right & 2 & $4.54 \%$ \\
& Bilateral & 1 & $2.27 \%$ \\
\hline CPA & Left & 2 & $4.54 \%$ \\
\hline
\end{tabular}


TABLE 3

Main clinical symptoms by cyst location

\begin{tabular}{|c|c|c|c|c|}
\hline Symptom Location & Sylvian fissure & Frontal lobe & CPA & Total \\
\hline Headache & $36(81.8 \%)$ & $2(4.55 \%)$ & $2(4,55 \%)$ & $40(90.9 \%)$ \\
\hline Epilepsy & $10(22.73 \%)$ & $3(6.82 \%)$ & 0 & 13 (29.55\%) \\
\hline $\begin{array}{c}\text { Dizziness/balance } \\
\text { impairment }\end{array}$ & $9(20.45 \%)$ & $1(2.3 \%)$ & $2(4.55 \%)$ & $12(29.3 \%)$ \\
\hline Personality changes & $1(2.3 \%)$ & $1(2.3 \%)$ & 0 & $2(4.55 \%)$ \\
\hline Hemiplegia & $1(2.3 \%)$ & 0 & 0 & $1(2.3 \%)$ \\
\hline
\end{tabular}

TABLE 4

Postoperative complications/reoperation due to complications or treatment failure

\begin{tabular}{|c|c|c|c|}
\hline Complication & Cyst shunting patients & Craniotomy patients & Overall \\
\hline Infectious & $1(7.1 \%)$ & $1(3.3 \%)$ & $2(4.5 \%)$ \\
\hline Subdural hematoma & 0 & $1(3.3 \%)$ & $1(2.3 \%)$ \\
\hline Epidural hematoma & 0 & $1(3.3 \%)$ & $1(2.3 \%)$ \\
\hline Revision of shunt $^{\text {New shunt }}{ }^{\star}$ & $4(28.6 \%)$ & 0 & $4(9.1 \%)$ \\
\hline Reoperation $^{\star}$ & $1(7.1 \%)$ & 0 & $1(2.3 \%)$ \\
\hline All complicatios & $5(35.7 \%)$ & $2(6.6 \%)$ & $7(15.9 \%)$ \\
\hline
\end{tabular}

$\wedge$ one of the patients developed secondary hydrocephalus and needed an aditional ventricular shunt $\star_{\text {not all complications required surgical treatment }}$
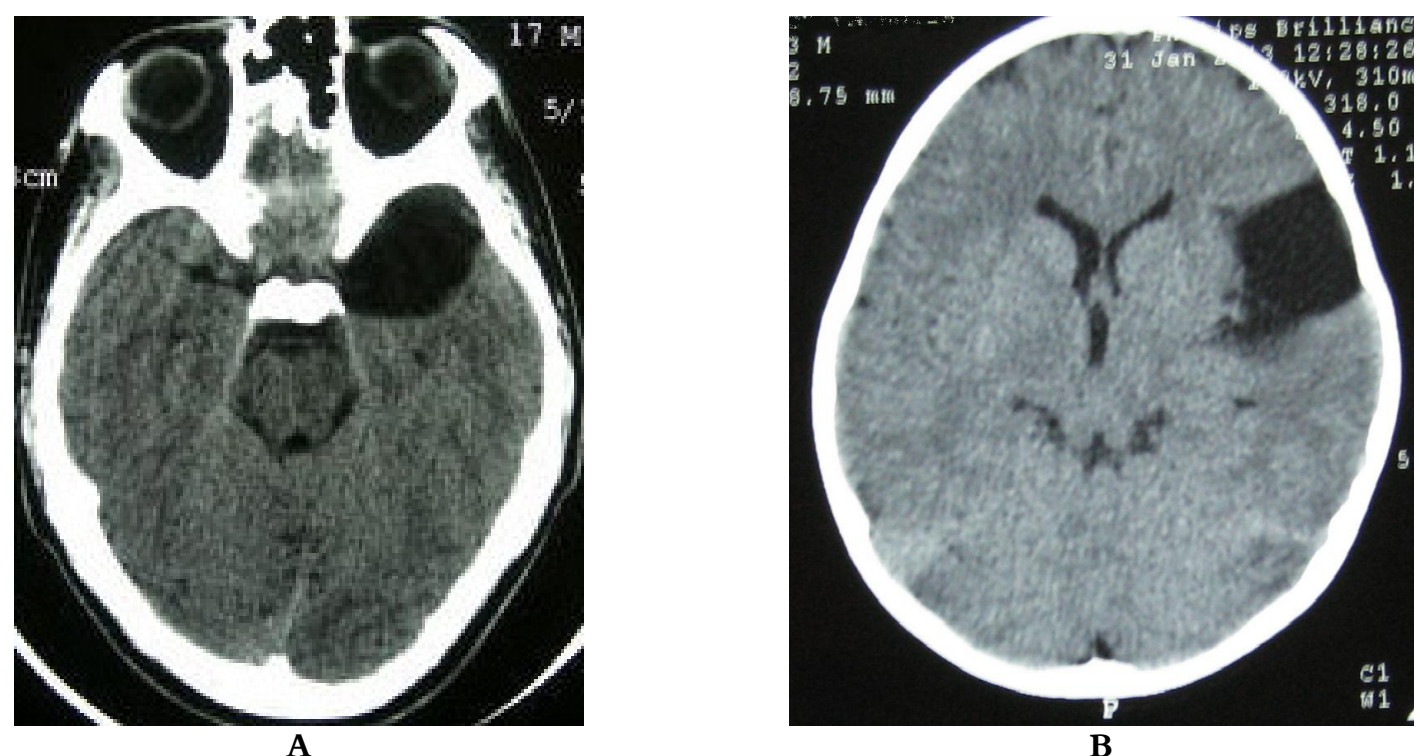


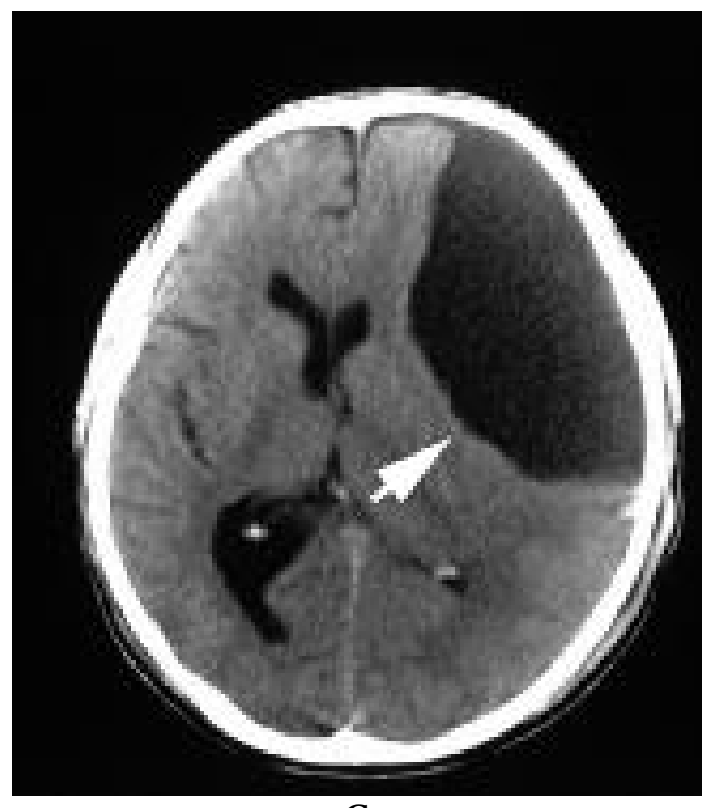

C

Figure 1

Sylvian fissure cysts - Galassi classification :

A. Type I: biconvex, located in the anterior temporal tip

B. Type II: insula is completely open; rectangular shape; it involves proximal and intermediate segments of sylvian fissure

C. Type III: involves entire sylvian fissure; important mass effect

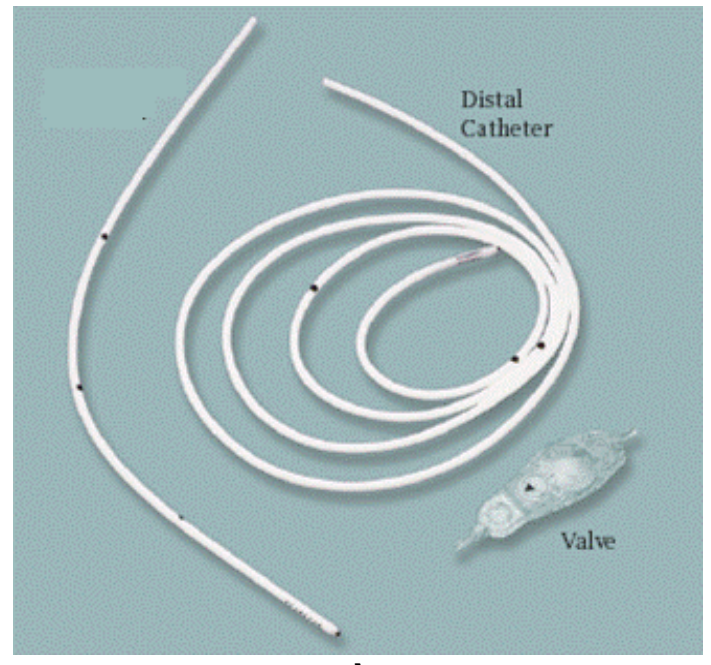

A

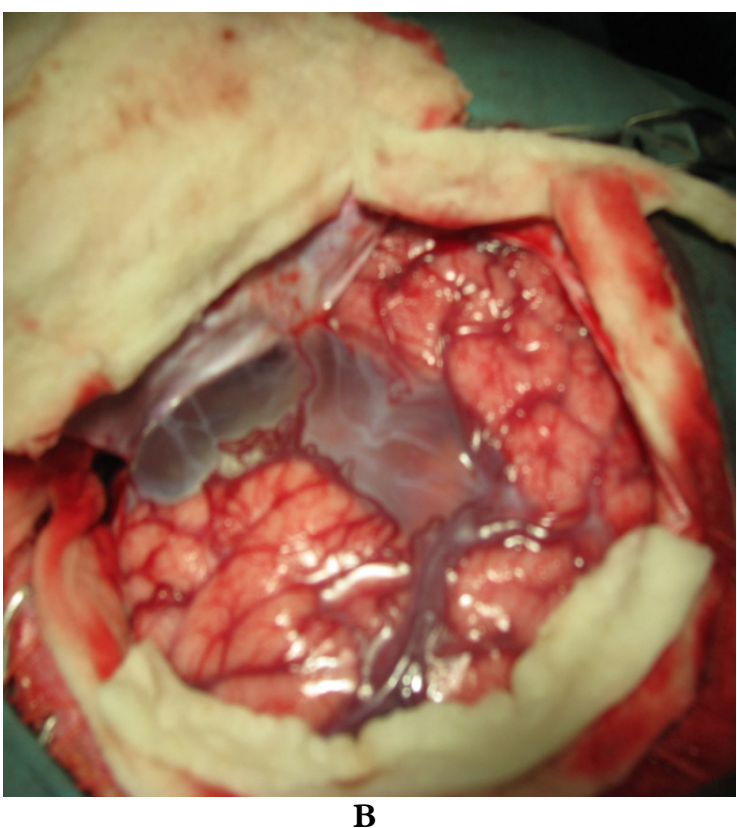

Figure 2

Surgical treatment : A. Cyst shunting;

B. Craniotomy

Intracranial hemorrhage in patients with arachnoid cysts: 16 patients (31.8\%) presented a hemorrhagic complication at admission (14 of them had a subdural hematoma and 2 presented with hemorrhage into the cyst. Minor head trauma in the last month was a common finding among them (81.25\%). Data statistical analysis showed that a history of minor head trauma in the past month is a risk factor for hemorrhagic complications of ACs - odds ratio $(\mathrm{OR})=56.33$, $\mathrm{p}=0.000004, \mathrm{CI}=(6.72,636.86)$.

Clinical outcome status: 37 patients (84.1\%) either no/minor complaints or the relief of symptoms postoperatively (a COS1 or COS2). $13.6 \%$ of the patients had no change in the clinical status after surgery (COS3), while only one patient complained of worse clinical status postoperatively (a COS4). The patient with the COS4 was one of the asymptomatic patients, with a compressive type III cyst and complained of 
headache/dizziness (the symptoms were no longer present 1 month later, at check-up). There is no significant statistical evidence that any of the two procedures results in a better clinical outcome (COS1/2) $\mathrm{p}=0.8$.

Imaging outcome aspect: $90.9 \%$ of the patients (40/44) showed either cyst disappearence (IOA1) or cyst reduction (IOA2) at the 3 month neuroimaging examinations, while $9.1 \%$ (4/44) showed no change in cysts dimensions (IOA3). All the IOA3 subgroup patients where operated by cystoperitoneal shunting. Craniotomy appears to result in a better neuroimaging aspect at 3 months $(p=0.02)$. There is no correlation between a good clinical outcome and cyst reduction/disappearance in imaging examination $(\mathrm{p}=0.6)$.

Postoperative complications/reoperation due to complications or treatment failure: $42.8 \%$ of the patiets treated by cystoperitoneal drainage presented complications/reinterventions due to failure of primary treatment, whereas only $10 \%$ of the patients where a craniotomy was performed presented with postperative complications. The type of complications for each of the two surgical procedures is detailed in Table4. However, the overall complications/reoperations due to failure of primary treatment rate of $20.4 \%$ and the lack of any severe or permanent postop deficiencies prove that surgery is an apropriate treatment for arachnoid cysts. Statistical analysis of the data proved that craniotomy is a risk factor for postoperative complications/reoperations $\quad-\quad \mathrm{RR}=4.3$ (relative risk), $\mathrm{RD}=32.8 \%$ (risk difference), $\mathrm{p}=0.019$.

\section{Discussion}

Our study results regarding the sex distribution, cyst location and symptoms frequency is similar to the data cited in the international specialized literature (1-11). There was a high percentage of patients that presented with hemorrhagic complications, the numbers rising the question whether or not ACs diagnosed in children should be operated on even though they are not symptomatic, considering the risk of bleeding associated with a history of head trauma and large arachnoid cysts $(23,24)$. The majority of patients that underwent surgical treatment had a good clinical and neuroimaging outcome and most of the patients had no complications and/or reoperations. Plus, none of the complications implies any severe/permanent dysfunction in any of the patients operated. Failure of treatment is associated more with cyst shunting than craniotomy, mostly because of the undershunting complications/reoperations that appear in most of the shunt dependant patients.

\section{Conclusions}

We clearly demonstrated that a history of minor head trauma in the past month represents a risk factor for cyst hemorrhage. Another conclusion is that surgical treatment of arachnoid cysts improves patients clinical symptoms, with little risk of severe postoperative complications, proving that surgery is an appropriate modality to improve patients quality of life, without causing damage. Also, craniotomy has a better neuroimaging outcome and a lower risk of complications than cyst shunting, making it the best procedure of the two. The high rate of reoperations associated with cyst shunting indicates that shunt dependence is a problem that we should avoid whenever possible. 


\section{References}

1. Youmans, Julian R, MD. Neurological Surgery:A Comprehensive Reference Guide to the Diagnosis and Management of Neurosurgical Problems. 4th ed. Philadelphia: Saunders, 1996.

2. Samii M, de Carvalho GA, Hinojosa M. Arachnoid cysts of the posterior fossa. [ed.] Ricardo Ramina, Paulo Henrique Pires Agiular and Marcos Tatagiba. Samii's Essentials in Neurosurgery. Berlin: Springer, 2008, 20, pp. 215-220.

3. AH, Kaye. Essential neurosurgery, 3rd ed. s.l.: Blackwell Publishing, 2005.

4. Brooks ML, Mater DP, Sataloff RT, et al. Intracanalicular arachnoid cyst mimicking acoustic neuroma: CT and MRI. 16, 1992, Comp Med Imag Graph, pp. 283-285.

5. Haberkamp TJ, Monsell EM, House WF, et al. Diagnosis and treatment of arachnoid cysts of the posterior fossa. 103, 1990, Otolaryngol Head Nack Surg, pp. 610-614.

6. Greenberg, Mark S., M.D. Handbook of Neurosurgery, 6th edition. New York: Thime, 2006.

7. Helland CA, Lund-Johansen M, Wester K. Location, sidedness, and sex distribution of intracranial arachnoid cysts in a population-based sample. nov 2010, Journal of neurosurgery, Vol. 113, pp. 934-939.

8. Kang JK, Lee KS, Lee IW, et al. Shunt-independent surgical treatment of middle cranial fossa arachnoid cysts in children. 2, feb 2000, Childs Nerv Syst, Vol. 16, pp. 111-116.

9. De Volder AG, Michel C, Thauvoy C, et al. Brain glucose utilisation in aquired childhood aphasia associated with a sylvian arachnoid cyst: recovery after shunting as demonstrated by PET. 1994, J Neurol Neurosurg Psychiatry, Vol. 57, pp. 296-300.

10. Raeder MB, Helland CA, Hugdahl $\mathrm{K}$, et al. Arachnoid cysts cause cognitive dificits that improve after surgery. 2005: s.n., Neurology, Vol. 64, pp. 160162.

11. Mayr U, Aichner F, Bauer G, et al. Supratentorial extracerebral cysts of the middle cranial fossa. A report of 23 consecutive cases of the so called temporal lobe agenesis syndrome. Stuttgart: s.n., 1982, Neurochirurgia, Vol. 25, pp. 51-56.

12. Osborn, Anne G et al. Diagnostic Imaging - Brain. 1st ed. Salt Lake City, Utah: AMIRSYS, 2004.
13. Kornienko, Valery $\mathrm{N}$. and Pronin, Igor $\mathrm{N}$. Diagnostic Neuroradiology. Berlin: Springer, 2009.

14. Auer LM, Gallhofer B, Ladurner G, et al. Diagnosisi and treatment of middle fossa arachnoid cysts and subdural hematomas. 3, March 1981, Journal of Neurosurgery, Vol. 54, pp. 366-369.

15. Helland CA, Wester K. A population-based study of intracranial arachnoid cysts: clinical and neuroimaging outcomes following surgical cyst decompression in children. 5 Suppl, Nov 2006, J Neurosurg, Vol. 105, pp. 385-390.

16. Ciricillo SF, Cogen PH, Harsh GR, et al. Intracranial arachnoid cysts in children. A xomparison of th effects of fenestrating and shunting. 2, Feb 1991, J Neurosurg, Vol. 74, pp. 230-235.

17. Kim SK, Cho BK, Chung YN, et al. Shunt dependancy in shunted arachnoid cyst: a reason to avoid shunting. 4, Oct 2002, Pediatr Neurosurg, Vol. 37, pp. 178-185.

18. Di Rocco C, Tamburrini G, Caldarelli M, et al. Prolonged ICP monitoring in children with sylvian fissure arachnoid cysts. 6, Dec 2003, Minerva Pediatr, Vol. 55, pp. 583-591.

19. Harsh GR IV, Edwards MS, Wilson CB. Intracranial arachnoid cysts in children. 1986, J Neurosurg, Vol. 64, pp. 835-842.

20. van der Meche FG, Braakman R. Arachnoid cysts in the middle cranial fossa: cause and treatment of progressive and non-progressive symptoms. 1983, J Neurol Neurosurg Psychiatry, Vol. 46, pp. 1102-1107.

21. Sommer IE, Smit LM. Congenital supratentorial arachnoid and giant cysts in children: a clinical study with arguments for a conservative approach. 1997, Childs Nerv Syst, Vol. 13, pp. 8-12.

22. Sato H, Sato M, Katayama S, et al. Effective shuntindependent treatment for primary middle fossa arachnoid cyst. 1991, Childs Nerv Syst, Vol. 7, pp. 375381.

23. Sprung C, Armbruster B, Koeppen D, et al. Arachnoid cysts of the middle cranial fossa accompanied by subdural effusieon-experience with 60 consecutive cases. 1, Wien: s.n., Jan 2011, Acta Neurchir, Vol. 153, pp. 75-84.

24. Cress M, Kestle JRW, Holubkov R, et al. Risk factors for pediatric arachnoid cyst rupture/hemorrhage: a case-control study. 5, May 2013, Neurosurgery, Vol. 72, pp. 716-722. 